\title{
Thalidomide Combined with Neoadjuvant Chemotherapy in Angiosarcoma of the Breast with Complete Pathologic Response: Case Report and Review of Literature
}

\author{
Alberto Alvarado-Miranda ${ }^{a} \quad$ Ludwing Bacon-Fonseca $^{\mathrm{a}} \quad$ Ulises Lara-Medina Fernando ${ }^{\mathrm{a}}$ \\ Hector Maldonado-Martínez ${ }^{b}$ Claudia Arce-Salinas ${ }^{a}$ \\ a'Medical Oncology Department,

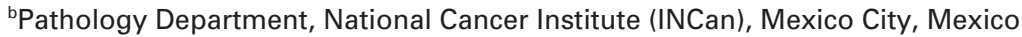

\section{Keywords}

Breast angiosarcoma . Thalidomide .

Pathologic complete response

\section{Summary}

Background: Primary angiosarcoma of the breast is a rare malignancy. Case Report: We report on a 41-year-old female patient who initially presented with locally advanced disease. Core biopsy showed angiosarcoma of the breast, grade 1, CD31-positive. The patient was treated with neoadjuvant systemic chemotherapy based on cisplatin, doxorubicin, and paclitaxel, given concurrently with thalidomide. After treatment completion, the patient underwent radical mastectomy. Pathologic complete response in the breast and axillary lymph nodes was achieved. The patient has no evidence of disease recurrence 6 months after her initial diagnosis. Conclusion: Anti-angiogenic therapy may be considered as part of the management of primary angiosarcoma of the breast.

\section{Introduction}

Primary angiosarcoma of the breast is a rare and highly aggressive tumor. It represents $0.04 \%$ of all breast tumors and approximately $8 \%$ of breast sarcomas [1,2]. It is most commonly observed in young patients (aged 30-50 years). These tumors have a poor prognosis with an 8-50\% 5-year survival [3]. These tumors usually develop as a complication of a preexisting condition, such as prior radiation or lymphedema [4]. The etiology of primary angiosarcoma remains unknown. Surgery continues to be the cornerstone of treatment. Radio- and chemotherapy have been attempted with varying results. Here we present a case of a 41-year-old premenopausal woman with primary angiosarcoma of the breast treated at our institute.

\author{
Schlüsselwörter \\ Angiosarkom der Brust · Thalidomid . \\ Komplette pathologische Remission
}

\section{Zusammenfassung}

Hintergrund: Das primäre Angiosarkom der Brust ist eine seltene Tumorerkrankung. Fallbericht: Wir berichten von einer 41-jährigen Patientin, die mit einem lokal fortgeschrittenen Mammakarzinom vorstellig wurde. Die Stanzbiopsie ergab ein Angiosarkom der Brust, Grad 1, CD31-positiv. Die Patientin erhielt neoadjuvante systemische Chemotherapie basierend auf Cisplatin, Doxorubicin und Paclitaxel gemeinsam verabreicht mit Thalidomid. Nach Abschluss der Chemotherapie wurde eine radikale Mastektomie durchgeführt. Eine komplette pathologische Remission wurde sowohl in der Brust als auch in der Axilla erzielt. Die Patientin ist 6 Monate nach Erstdiagnose frei von Krankheitsanzeichen. Schlussfolgerung: Die antiangiogene Therapie sollte als Bestandteil der Behandlung des primären Angiosarkoms der Brust in Erwägung gezogen werden.

\section{Case Report}

A 41-year-old premenopausal woman presented with a lump in her left breast. There was no previous history of radiation or any other comorbidity. On physical examination, the patient had a tumor located in the lower outer quadrant of the left breast, $12 \times 9 \mathrm{~cm}$ in diameter, with skin infiltration and a palpable axillary node measuring $3.5 \mathrm{~cm}$ in diameter. Mammography showed a lesion highly suspicious of cancer, classified as BIRADS 5 (Breast Imaging Reporting and Data System). Core biopsy reported angiosarcoma grade 1, CD 34-negative and CD 31-positive (fig. 1). Chest X-ray, bone scan, and abdominal ultrasound (US) showed no evidence of metastatic disease. The patient was treated with neoadjuvant chemotherapy based on doxorubicin and cisplatin at doses of $50 \mathrm{mg} / \mathrm{m}^{2}$ and $75 \mathrm{mg} / \mathrm{m}^{2}$, respectively, in combination with thalidomide $200 \mathrm{mg}$ total dose, for 4 cycles every 21 days, followed by weekly paclitaxel and cisplatin $80 \mathrm{mg} / \mathrm{m}^{2}$ and $30 \mathrm{mg} / \mathrm{m}^{2}$, respectively, also in combination with thalidomide

\begin{tabular}{ll}
\hline KARGER & ( ) 2013 S. Karger GmbH, Freiburg \\
Fax +49 761452 $520714-3791 / 13 / 0081-0074 \$ 38.00 / 0$ \\
$\begin{array}{l}\text { Information@Karger.com } \\
\text { www.karger.com }\end{array}$ & $\begin{array}{l}\text { Accessible online at: } \\
\text { www.karger.com/brc }\end{array}$
\end{tabular}



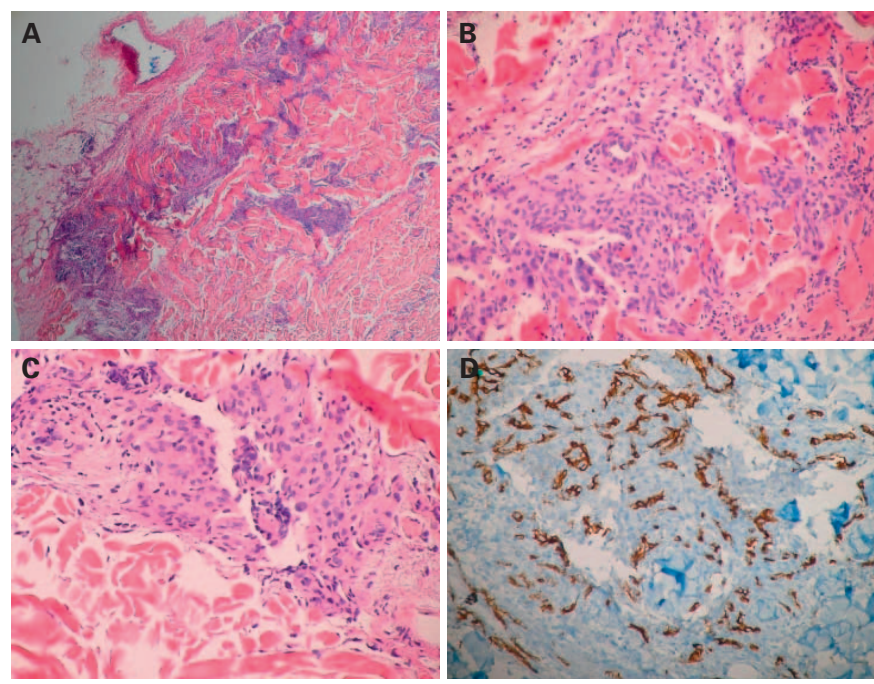

Fig. 1. Photomicrographs from the initial biopsy of the patient. A Neoplasm diffusely infiltrating and dissecting the interlobular stroma at the interphase between the reticular dermis and the hypodermis. B Neoplasm showing anastomosing vascular channels with prominent endothelium, hyperchromatic nuclei, and increased proliferation. C Some endothelial tufting may be seen in some areas. D Immunohistochemistry demonstrating the endothelial nature of the neoplastic cells which are CD31-positive.
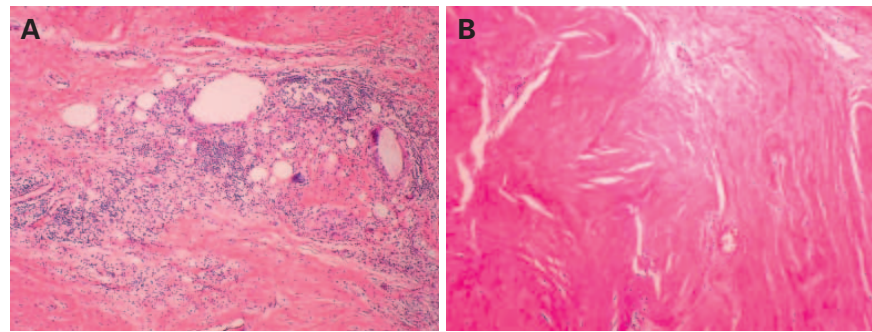

Fig. 2. Postchemotherapy mastectomy. A Image demonstrating necrotic and fibrotic areas following adjuvant treatment with chemotherapy. Vessels are scarce and lined with well differentiated endothelium. B In other areas fibrosis is the dominant feature.

at the same dose. The patient developed neutropenia grade 2 and 3 , and required support with granulocyte colony-stimulating factor (G-CSF). After chemotherapy, she achieved a clinical partial response (PR) with illdefined residual disease measuring $<2 \mathrm{~cm}$. The patient underwent mastectomy (both pectoral muscles were preserved, nodes in the axilla were removed in continuity with the breast and overlying skin); complete axillary dissection was not done. The pathology review showed fibrosis, absence of tumor, and 11 axillary nodes with hyperplasia (fig. 2). The patient received adjuvant radiotherapy to the chest wall at $50 \mathrm{~Gy}$. She is recurrence-free 6 months after treatment completion.

\section{Discussion}

Angiosarcoma can arise in any anatomic site, mainly in skin or soft tissue. Clinicopathological presentations include cutaneous angiosarcoma, lymphedema-associated angiosarcoma, radiation-induced angiosarcoma, primary-breast angiosarcoma, and soft tissue angiosarcoma [5]. The etiology of majority of cases of angiosarcoma is unknown. The tumors may develop as a complication of a preexisting condition such as chronic lymphedema (radical mastectomy - Stewart-Treves syndrome, or radical inguinal lymphadenectomy - Kettle's syndrome), radiotherapy, foreign material introduced into the body, and environmental carcinogens such as arsenic, dioxin, and vinyl chloride [5]. Angiosarcoma of the breast is classified as primary if it occurs sporadically in a young woman, usually presenting as a palpable mass. Secondary breast angiosarcomas occur most frequently in patients who have a history of breast cancer treated with conservative surgery followed by radiation therapy; the average latency period is 5-6 years [6]. In this setting the risk of developing angiosarcoma could be as high as 16 -fold (95\% confidence interval (CI) 6.6-38.0) according to the data revised by Monroe et al. [7]. These tumors tend to develop 4-7 years after therapy, and may be due to persistent lymphedema.

The diagnosis of angiosarcoma can be challenging. The mammogram may show a nonspecific mass, and up to one third of patients have no abnormalities [8]. Magnetic resonance imaging (MRI) has become a useful diagnostic tool [9]. As in our clinical case, mammographic findings may be non-specific. Histologically, angiosarcomas of the breast are classified into 3 grades (grade 1-3) or as well to poorly differentiated. It was believed that histologic grading of mammary angiosarcomas played an important role in determining the prognosis, but a recent study has shown that there no correlation between histologic grade and patient outcome [10]. Differential diagnosis of this rare malignancy includes benign hemangioma, cystosarcoma phyllodes, stromal sarcoma, metaplastic carcinoma, squamous cell carcinoma with sarcomatoid features, myoepithelioma, fibromatosis, fibrosarcoma, liposarcoma, and reactive spindle cell proliferative lesions. Immunohistochemistry can show positivity for factor VIII antigen, CD34, CD31, desmin, and vimentin. CD31 appears to be the most promising marker [6]. In our case, positivity of CD31 in association with the pathologic features confirmed the diagnosis.

Treatment is primarily surgical, either by mastectomy or wide excision [10]. There is no role for axillary dissection due to the low incidence of axillary metastasis [11]. However, when nodal involvement is suspected, axillary dissection is recommended [12]. In the present case, the patient had nodal involvement at the time of diagnosis. However, this clinical finding did not have pathological correlation. The role of adjuvant therapy with radiotherapy and chemotherapy is equivocal. This is because of small sample size in previous studies and selection bias. Although there is no survival advantage, adjuvant radiotherapy has shown to reduce local recurrence of the tumor [11]. It is reasonable to offer radiotherapy if there is a high risk of microscopic residual disease.

Metastatic tumors have shown response to combination cytotoxic chemotherapy (up to $48 \%$ ), which suggests that angiosarcoma is likely to be a chemosensitive disease. Many different anticancer drug combinations, including cisplatin with doxorubicin, cisplatin plus paclitaxel, and cisplatin plus doxorubicin plus paclitaxel [13], have recently been tested. Asmane et al. [14] reported 3 cases of metastatic or locally 
advanced angiosarcoma treated with doxorubicin, cisplatin, ifosfamide, and paclitaxel; the authors found PR in $75 \%$ of cases, and all of these patients were alive at 1 year of follow up. The patient cited in this case report was treated with a combination of cisplatin, paclitaxel, and doxorubicin, which was well tolerated and confirmed the efficacy of the approach in terms of clinical and pathological response. Main toxicity was neutropenia grade 2-3 resolved with prophylactic CSF-G.

Hashimoto et al. [15] recently published preliminary data suggesting that vascular endothelial growth factor (VEGF) and its receptor might be responsible for the paracrine- or autocrine-stimulated proliferation of some breast angiosarcomas. Immunohistochemical data from Itakura et al. [16] demonstrated positive VEGFR-3 expression in 27 of 34 (79\%) angiosarcomas; however none of these had breast origin. Gennaro et al. [12], searching for VEGF re-expression, determined its expression levels in 20 breast specimens and found a significant association with low- and intermediate-grade tumors, suggesting the role of VEGF in the early carcinogenesis of angiosarcoma. In our case, thalidomide was chosen for its anti-angiogenic and -inflammatory properties [17]. The primary mechanisms include effects on the tumor microenvironment, VEGF, plasma cell apoptosis, and angiogenesis $[18,19]$. This was supported by the clinical case reported by Raina et al. [20] who achieved complete response after treatment with thalidomide alone in the treatment of secondary angiosarcoma. Regarding other anti-angiogenic therapies, there is a small amount of evidence based on case report findings of the benefit of bevacizumab with or without chemotherapy; however none of these cases were breast angiosarcomas [21, 22].
Angiosarcoma carries a poor prognosis. 5-year survival ranges from $8-50 \%$ [3]. Hodgson et al. [23] reported the Ontario experience of 70 cases of angiosarcoma, with mortalities of 44 and $58 \%$ for primary or secondary angiosarcoma, respectively. The Mayo Clinic experience, reported by Scow et al. [24], showed 5-year survival for primary and secondary angiosarcoma of 46 and $69 \%$, respectively. And finally the MD Anderson Cancer Center experience of 55 cases [25] reported a median overall survival of 2.96 years (95\% CI 1.60-4.32). With better survival rates for those patients with localized disease at presentation, at 2 and 5 years overall survival rates were 90 and $59 \%$, respectively. The authors also reported a relapse rate of $30 \%$ which is similar to other sarcomas.

\section{Conclusion}

Primary angiosarcoma of the breast is a rare disease, surgery remains the cornerstone of treatment, and there is no evidence of a benefit of radiotherapy or chemotherapy as adjuvant treatment because of the lack of randomized studies. However recent evidence shows the important role of the angiogenesis process during the early stages of disease; thus the introduction of anti-angiogenic therapy may be considered as part of the management of this disease.

\section{Disclosure Statement}

The authors have nothing to disclose.

\section{References}

1 Agarwal PK, Mehrotra R: Haemangiosarcoma of 11 Chen KT, Kirkegaard DD, Bocian JJ: Angiothe breast. Indian J Cancer 1977;14:182-5.

2 Álvarez-Fernández E, Salinero-Paniagua E: Vascular tumors of the mammary gland. Virchows Arch A Pathol Anat Histol 1981;394:31-47.

$\checkmark 3$ Merino MJ, Carter D, Berman M: Angiosarcoma of the breast. Am J Surg Pathol 1983;7:53-60.

4 Huang J, Mackillop WJ: Increased risk of soft tissue sarcoma after radiotherapy in women with breast carcinoma. Cancer 2001;92:172-80.

$\checkmark 5$ Young RJ, Brown NJ, Reed MW, Hughes D, Woll PJ: Angiosarcoma. Lancet Oncol 2010:11;983-91.

6 Brenn T, Fletcher CD: Postradiation vascular proliferations: an increasing problem. Histopathology 2006;48:106-14.

7 Monroe AT, Feigenberg SJ, Mendenhall NP: Angiosarcoma after breast conserving therapy. Cancer 2003;97:1832-40.

8 Liberman L, Dershaw DD, Kaufman RJ, Rosen PP: Angiosarcoma of the breast. Radiology 1992; 183:649-54.

$\checkmark 9$ Yang WT, Hennessy BT, Dryden MJ, et al.: Mammary angiosarcomas: imaging findings in 24 patients. Radiology 2007;242:725-34.

10 Nascimento AF, Raut CP, Fletcher CD: Primary angiosarcoma of the breast: clinicopathologic analysis of 49 cases, suggesting that grade is not prognostic. Am J Surg Pathol 2008;32:1896-904. sarcoma of the breast. Cancer 1980;46:268-71.

12 Gennaro M, Valeri B, Casalini P, et al.: Angiosarcoma of the breast and vascular endothelial growth factor receptor. Tumori 2010;96:930-5.

13 Mathew P, Vakar-López F, Trocoso P: Protracted remission of metastatic epithelioid angiosarcoma with weekly infusion of doxorubicin, paclitaxel, and cisplatin. Lancet Oncol 2006;7:92-3.

14 Asmane I, Litique V, Heymann S, et al.: Adriamycin, cisplatin, ifosfamide and paclitaxel combination as front-line chemotherapy for locally advanced and metastatic angiosarcoma. Analysis of three case reports and review of the literature. Anticancer Res 2008;28:3041-6.

15 Hashimoto M, Ohsawa M, Ohnishi A, et al.: Expression of vascular endothelial growth factor and its receptor mRNA in angiosarcoma. Lab Invest 1995;73:859-63.

16 Itakura E, Yamamoto H, Oda Y, et al.: Detection and characterization of vascular endothelial growth factors and their receptors in a series of angiosarcomas. J Surg Oncol 2008;97:74-81.

17 Aragón-Ching JB, Li H, Gardner ER, et al.: Thalidomide analogues as anticancer drugs. Recent Pat Anticancer Drug Discov 2007;2:167-74.

18 Vacca A, Scavelli C, Montefusco V, et al.: Thalidomide downregulates angiogenic genes in bone marrow endothelial cells of patients with active multiple myeloma. J Clin Oncol 2005; 23: 534-46.

19 Balasubramanian L, Evans AM: Targeting angiogenesis for the treatment of sarcoma. Curr Opin Oncol 2006: 18:354-359.

20 Raina V, Sengar M, Shukla NK, et al.: Complete response from thalidomide in angiosarcoma after treatment of breast cancer. J Clin Oncol 2007;25:900-1.

21 Fuller C, Charlson JA, Dankle SK, et al.: Dramatic improvement of inoperable angiosarcoma with combination paclitaxel and bevacizumab chemotherapy J Am Acad Dermatol 2010; 63:83-4.

-22 De Yao JT, Sun D, Powell AT, et al.: Scalp angiosarcoma remission with remission with bevacizumab and radiotherapy without surgery: a case report and review of the literature. Sarcoma 2011;2011:160369.

23 Hodgson NC, Bowen-Wells C, Moffat F, et al.: Angiosarcomas of the breast. A review of 70 cases. Am J Clin Oncol 2007;30:570-3.

24 Scow JS, Reynolds CA, Degnim AC, et al. Primary and secondary angiosarcoma of the breast: the Mayo Clinic Experience. J Surg Oncol 2010; 101:401-7.

25 Borburger SA, Yan X, Hunt KK, et al.: Angiosarcoma of the breast. Cancer 2005;104:2682-8. 